\title{
STABILITY OF GOLD STANDARD AND ITS SELECTED CONSEQUENCES
}

\author{
MICHAL KVASNIČKA*
}

\begin{abstract}
The gold standard was quite stable in the past: the price level changes were relatively small, and trade cycles mild. However, its past stability does not guarantee stability nowadays. We show that the stability of the gold standard to shocks stemming from the world gold market depends critically on the size of the monetary stock of gold relative to the extent of these shocks. Every change decreasing the relative size of the monetary stock of gold lowers its stability. We discuss some consequences of the thesis too: first, any system economizing on its gold reserves (e.g. the mature fractional reserve free banking system of the Scottish type) may undermine the stability of the gold standard. Second, an attempt to reestablish the gold standard may have to include a collective action of many countries of a great economic power. If a single small country tried to resume to the gold, its monetary stock of gold would probably be tiny relative to the world gold market shocks, and the economy could be destabilized by these shocks. It makes the return of the gold standard rather improbable in the near future.
\end{abstract}

Key words: Gold Standard, Stability, Inflation, Trade Cycle.

JEL Classification: E31, E39, E42, N10.

\section{I \\ INTRODUCTION}

Some economists of the Austrian school have in the last decades proposed abandoning the present monetary system in which private fractional reserve banks issue liabilities convertible to a

\footnotetext{
* Ph.D., Masaryk University, Faculty of Economics, qasar@econ.muni.cz
} 
local fiat money issued by a monopoly state-owned central bank, and to reestablish some form of a commodity standard, usually a gold one, ${ }^{1}$ and replace the central banking system with some kind of free banking system.

Reasons to 'prefer gold' are many; among them two are perhaps the most striking: first, the gold standard is the system most independent of government interventions of all known monetary systems. The second major reason is the historical stability of the gold standard. Until it was manipulated and eventually spoiled by governments, the gold standard provided quite stable prices (at least in comparison with the outcomes of fiat money issued by central banks in the 20th century, see e.g. Rolnick-Weber,1997), and only mild trade cycles (at least in comparison to recessions known from the 20th century, especially the Great Depression of the 1930s).

However, the historical stability of the gold standard does not guarantee its stability nowadays too, and hence whether it is desirable at all to reestablish it. For this reason we question its stability in this paper. For our purposes we understand the stability of the gold standard as the stability of the price level, and absence of trade cycles. It seems reasonable to consider these two together, since according to most trade cycle hypotheses, these two factors are interconnected. While exploring its stability, we will examine only consequences of one particular type of shocks-the shocks caused by the gold standard itself, i.e. by changes in gold mining, of industrial gold consumption, and of the impetus for holding non-monetary stocks of gold; we will not discuss the consequences of other types of shocks.

We will show that the stability of the gold standard in relation to the selected type of shocks depends on the size of the monetary stock of gold relative to the extent of these shocks. The higher the monetary stock of gold relative to the extent of these shocks, the more stable the price level when such a shock occurs. It

1 It does not matter whether the commodity standard is based on gold, silver, or other commodity with suitable characteristics. We will speak about the gold standard instead of a single-commodity standard to simplify matters. Anything stated below holds true for any single-commodity standard. 
means that an economy under the gold standard in a world of a tiny monetary stock of gold could suffer serious instability. (For the stability in relation to a monetary shock, i.e. to a sudden change in the demand for money, holds the opposite; however, we will not question this problem here.)

To prove this thesis, we have to sketch a model of the gold standard (section 2), and explore its features, especially its dynamics (section 3). We will also discuss some implications of the thesis for the mature fractional reserve free banking system of a Scottish type, and of attempts to resume convertibility (section 4).

\section{II MODEL OF GOLD STANDARD}

To explore the properties and stability of the gold standard, we will use a simple model derived by White (1999). It allows us to avoid algebra, and to present the model in an intuitive and easyto-grasp way. (Those in love with algebra may take a look at the appendix, which sketches the argument in a slightly more formal way.) While the model is roughly compatible with other standard models of the gold standard, like Barro (1979), Dowd-Sampson (1993), or Chappell-Dowd (1997), it does not include special assumptions about the gold depletion, the process of adjustment of the actual non-monetary stock of gold to its target level, or a particular relation of the gold consumption to the aggregate product.

For the sake of simplicity, we assume a stationary closed economy under the gold standard-all gold countries form one single economy within which gold can flow without any cost, or restrictions, i.e. the purchasing power of gold is the same everywhere. Money may be either full-bodied coins, or claims on banks redeemable in gold; bank money can be either money substitutes, or fiduciary media, i.e. the money multiplier can be one or higher. To simplify matters further, we assume that the unit of money is the weight unit of gold, troy ounce (tr. oz.). We call all gold held for the monetary purposes (golden coins in 
circulation, and gold reserves in bank vaults) the monetary stock of gold.

Under the gold standard, gold is used not only for monetary purposes, but for non-monetary ones as well. There are two types of non-monetary use of gold: consumptive and nonconsumptive. The gold consumed (e.g. included in computer circuits) cannot be drawn back at a reasonable cost. Thus it constitutes an irreversible outflow of gold out of the economy. On the other hand, the non-consumptive use (e.g. holding jewelry for ornamental reasons) is reversible-it constitutes the nonmonetary stock of gold that can be reused at any time for any purpose.

We assume that gold in the non-monetary stock can be minted, and gold in the monetary stock can be melted down free of charge, i.e. gold can flow from monetary to non-monetary use and vice versa without restrictions, which equalizes its purchasing power in each of its uses. Our assumptions secure that the purchasing power of money (the inverse value of the price level) is the same as the purchasing power of gold, regardless of whether the particular piece of gold is held for monetary or non-monetary purposes.

Under our assumptions the quantity of money is at any moment determined by the size of the monetary stock of gold, and the monetary multiplier-it is their multiple. The size of the monetary stock of gold is determined by the gold standard; the monetary multiplier is determined by the preferences of the public for the structure of its money balances, and by reserve requirements of banks.

The momentary price level is at any moment determined by the momentary supply of money, and the momentary demand for it. Thus for a given demand for money any change in the size of the monetary stock of gold changes the quantity of money, and hence the price level. Since the quantity of money is a multiple of the size of the monetary stock of gold, we can also say that the momentary price level is determined by the momentary supply of the monetary stock of gold, and the momentary demand for it - where the demand for the monetary gold is the demand for money divided by the monetary multiplier. For this reason, 
the demand for the monetary stock of gold $G_{m}^{d}$ rises with the rise of the price level $P$, i.e. decreasing with the rise of the purchasing power of gold $(1 / P)$, see the right side of Figure 1 .

The size of the monetary stock of gold is not constant even in the very short run. It is so because it constitutes only a fraction of the total stock of gold available at that moment in the economy. The other part is the non-monetary stock of gold. Since any particular piece of gold can flow freely from one stock to the other, the momentary supply of the monetary stock of gold is given as the momentary total stock of gold in the economy minus the quantity demanded for the non-consumptive non-monetary use (let us assume for simplicity's sake that the size of the nonmonetary stock of gold is always equal to its demanded quantity). The demand for the non-monetary stock of gold rises with the price level since it makes gold cheaper in terms of goods. Thus for a given size of the total stock of gold, the supply of the monetary stock of gold $G_{m}^{s}$ decreases with the rise of the price level since more gold is demanded for the non-monetary stock, see Figure 1.

The size of the total stock of gold itself is not constant over time. It is increased by a quantity of newly mined gold per period

\section{FIGURE 1}
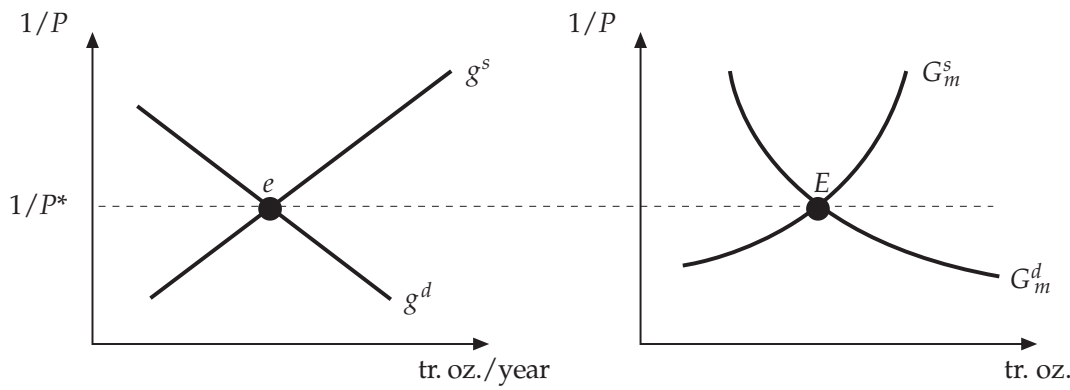

The long run equilibrium of a gold economy. The actual price level $P^{*}$ is determined by the supply of the monetary stock of gold $G_{m}^{s}$, and the demand for it $G_{m}^{d}$. In the long run equilibrium, the price level is such that the same quantity of gold is mined (given the supply of newly mined gold $g^{s}$ ) as is consumed (given the consumptive demand for gold $g^{d}$ ), i.e. the total stock of gold is constant over the time, not pressing for the change of the price level. 
of time, and decreased by the consumptive use of gold per period of time, i.e. it rises if more gold is mined than consumed, and goes down if the opposite holds true. The supply of the newly mined gold $g^{s}$ is higher the lower the price level is because it make gold mining more profitable, see the 'flow' supply curve $g^{s}$ in the left part of Figure 1. The opposite holds true for the consumptive demand for gold $g^{d}$ because a decrease in the price level makes the consumptive use of gold more costly, see the 'flow' supply curve $g^{d}$ in Figure 1. These 'flow' supply and demand, and the demand for the non-monetary stock of gold may depend on other variables too, e.g. on the size of the aggregate product, the size of the monetary stock of gold etc. We will neglect these possible relationships since they are not important for our analysis.

Since the total quantity of gold available to the economy is not constant over time but is changed by any surplus or deficit of mining over the consumptive use of gold, the price level determined by a momentary monetary gold supply need not be the long run equilibrium. Let us suppose that at the actual price level more gold is mined than consumed. In such a case the total quantity of gold rises. Some gold is added to the monetary stock of gold, which expands the actual quantity of money, which in turn raises the actual price level. As the price level rises, some gold is transferred from the monetary stock to the non-monetary stock, since at the higher price level more gold is demanded for this purpose. Moreover, less gold is mined, and more is consumed at the higher price level. The process continues until the price level is reached at which the same quantity of gold is both mined, and consumed. This is the long run equilibrium price level. If at the actual price level less gold is mined then consumed, the process goes in the opposite direction until the long run equilibrium price level is reached. Thus the actual price level is always determined by the momentary supply of the monetary stock of gold, and the momentary demand for it, while the long run equilibrium is determined by gold 'flows'. For a formal analysis of the steady state see Barro (1979); for an analysis of a steady growth see White (1999). 
III

\section{REACTION TO SHOCKS}

There is no need to discuss properties of the gold standard in detail here. An interested reader may see the works quoted above. Only two propositions are important for us: first, any change in the demand for a stock of gold (either the monetary or non-monetary one) changes the price level only temporarily. The change of the price level caused by such a shock creates an imbalance between the quantity of gold mined and consumed. Gold is then either added to or subtracted from the total stock of gold, which changes the price level until the original long-run equilibrium price level is reestablished, see Figure 2.

Secondly, any change of the 'gold flows', i.e. of the supply of newly mined gold $g^{s}$, or of the consumptive demand for gold $g^{d}$ changes the long-run equilibrium-the price level changes permanently. If either the flow supply, or the flow demand curve is shifted by a shock then there is an imbalance between the quantity of newly mined gold and the quantity of gold consumed at the actual price level. Gold is either added to or subtracted

\section{FIGURE 2}

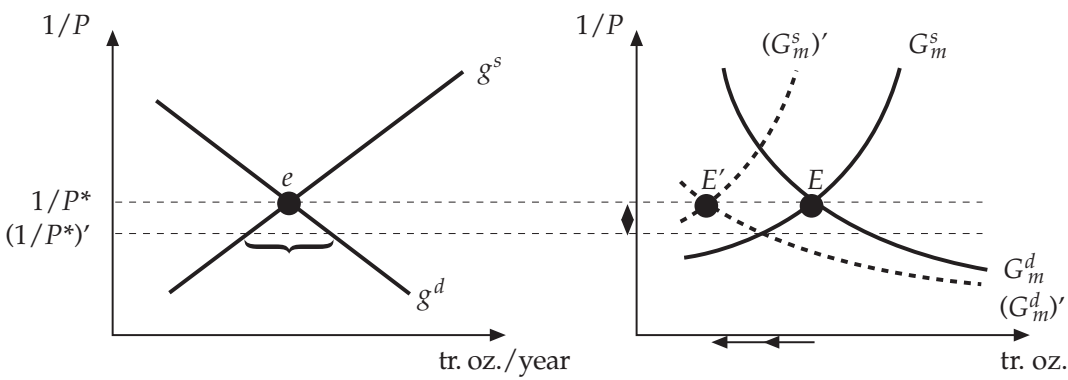

An example of a change in a demand for gold stock. Let us assume a decrease of the demand for money. It lowers the demand for the monetary stock of gold $G_{m}^{d}$ to $\left(G_{m}^{d}\right)^{\prime}$, which raises the price level from $P^{*}$ to $\left(P^{*}\right)^{\prime}$. At the higher price level more gold is consumed than mined-the difference (denoted by the brace) is subtracted from the total stock of gold, which shifts the supply of the monetary stock of gold $G_{m}^{s}$ to the left, which in turn lowers the price level. The process continues until the original price level $P^{*}$ is attained. 
from the total gold stock changing the price level until a new long run equilibrium is reached, see Figure 3.

In this way the gold standard roughly stabilizes the price level. ${ }^{2}$ This virtue of the gold standard is well known. What deserves special interest is the dynamics of the system, especially the speed with which a new long-run equilibrium price level is reached after a shock. The speed of the transition from the old to the new equilibrium is influenced by many factors, especially by price elasticity of the consumptive demand for gold, of the supply of the newly mined gold, and of the demand for the monetary, and for the non-monetary stock of gold. It is impossible to say anything meaningful about these factors in general. However, there is one important factor-the relative size of the monetary stock of gold - that significantly affects the price level stability in each case.

\section{FIGURE 3}

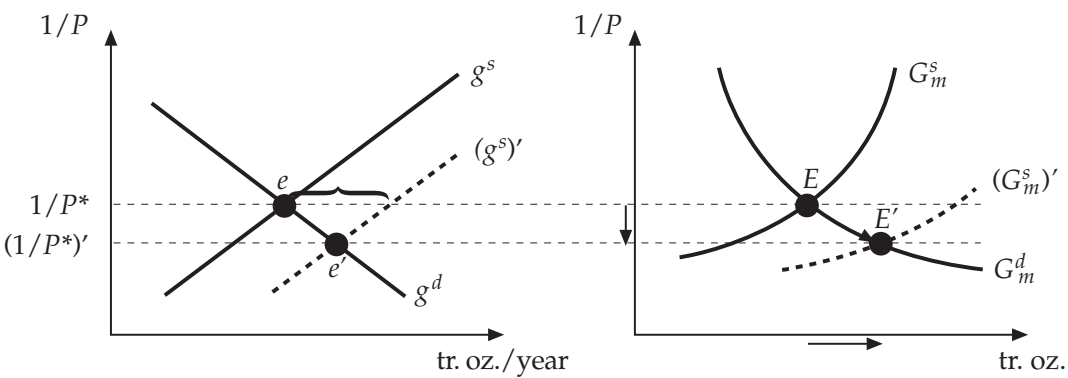

An example of a change of the 'flow' demand or supply. Let us assume an improvement in the mining technology, which shifts the supply of newly mined gold $g^{s}$ to the right to $\left(g^{s}\right)^{\prime}$. Now there is an imbalance (denoted by the brace) between the quantity of the newly mined gold and the quantity of gold consumed at the present price level. The surplus is added to the total stock of gold shifting the monetary supply of gold $G_{m}^{s}$ to the right, which raises the price level. The price level rises until the new higher long-run equilibrium price level $\left(P^{*}\right)^{\prime}$ is reached.

2 Barro (1979) gets slightly different result for a growing economy since he assumes that the consumptive demand for gold rises with the rise of GDP. We will not discuss this case in details since it does not change our thesis. 
The monetary stock of gold acts like a cushion dampening the 'gold' shocks: the higher it is, the more stable the price level is. The transition to a new long run equilibrium is slower (and the associated rate of change of the quantity of money, and inflation or deflation is lower) the higher this cushion is relative to extent of the shock. The reason is simple: any surplus of gold is added to the monetary stock of gold (a deficit does the opposite). The size of this surplus or deficit is independent of the present size of the monetary stock of gold. Then, the lower the monetary stock of gold is, the higher its percentage change in a case of an imbalance is. The higher the percentage change of the monetary gold stock is, the higher the percentage change of the quantity of money is, and hence the percentage change of the price level, i.e. the price inflation or deflation. See Figure 3: the extent of the imbalance between the quantity of newly mined gold and gold consumed is denoted by the brace. How far to the right it shifts the supply of the monetary stock of gold depends on its relative size to the size of the monetary stock of gold. Note that the horizontal axes of the two parts of the Figure 3 have different scales.

A numerical case may illustrate this well. Let us suppose that a new gold field was discovered. The supply of newly mined gold $g^{s}$ is shifted to the right, and there is a surplus of newly mined gold over its consumption at the present price level. The size of the imbalance is independent of the size of the monetary stock of gold. Let us say that the surplus is one million troy ounces per year. Now, if the monetary stock of gold is large, let us say one hundred billion troy ounces, it is increased by less than one to one thousand percent in a year, or even less because it lowers the purchasing power of gold slightly, and thus a part of the surplus is shifted to the non-monetary stock of gold. In such a case we may expect only negligible price inflation, and a very slow transition to the new equilibrium price level. On the other hand, if the monetary stock of gold was for instance only one million troy ounces, its percentage change would be quite high-between zero and one hundred percent per year depending on the price elasticity of the demand for the non-monetary stock of gold. Even if this demand was quite price-elastic, the price 
inflation associated with the shock would be quite high. Moreover, it may be at its outset enhanced by a decrease in the demand for the monetary stock of gold because the public facing the high price inflation would decrease its demand for the real money balances.

Interesting empirical evidence supporting this thesis may be found in Radford's paper «The Economic Organization of a P.O.W. Camp» (Radford, 1945). In the Prisoner of War Camp where Mr. Radford was detained, cigarettes evolved into the general media of exchange. He writes: «At one time in the early days, before any private parcels had arrived and when there were no individual stocks, the weekly issue of cigarettes and food parcels occurred on a Monday. The non-monetary demand for cigarettes was great, and less elastic than demand for food: consequently prices fluctuated weekly falling towards Sunday night and rising sharply on Monday morning. Later, when many people held reserves, the weekly issue had no such effect, being too small a proportion of the total available.»

If the demand for the non-monetary gold stock changes, the process is slightly more complex but the major thesis remains the same. Let us suppose an increase in the demand for gold held for ornamental purposes. The extra-demanded gold is first subtracted from the monetary stock of gold. The price level would change more the higher the percentage change of the monetary stock of gold is-which depends on the size of the shock relative to the magnitude of the monetary stock of gold. As soon as the price level is affected, the process described above is set in motion: more gold is mined than consumed in this case, which raises the price level to the former long run equilibrium level. Thus price deflation is followed by price inflation in this case. Both of them are more severe the lower the monetary stock of gold relative to the extent of the shocks is.

When the monetary stock of gold is relatively small, we may expect not only relatively higher inflation or deflation caused by the factors discussed above, but also more severe trade cycles. This conclusion is obvious to those who believe that trade cycles are caused by changes of the aggregate price level (as for example the Monetarists and other monetary-misperceptions, or all kinds 
of Keynesians do) ${ }^{3}$; but it holds good even if one sticks to the Austrian trade cycle theory. It is so because the change of the price level is just a consequence of the previous money expansion or contraction. The lower the monetary stock of gold is, the higher the percentage money expansion or contraction is-and this way the more severe the impact on the economy is. ${ }^{4,5}$

\section{IV SELECTED CONSEQUENCES}

The hypothesis sketched above has some consequences that Austrian economists might not welcome. We will stress two of them: first, we will show that the free banking system of the

3 The occurrence of the trade cycle may depend on expectations-an expected change of the price level need not to cause it. But it is hard to believe that the price level change caused by a shock of the kind we are dealing with could be expected precisely even at its outset.

4 We assume that Mises and Hayek were right that any change in the quantity of money causes trade cycles, i.e. that Rothbard (1963, p. 34-36) was wrong when he stated that the expansion of the monetary stock of gold does not cause it. Anyway, even Rothbard would agree that the expansion of the fiduciary media allowed by the expansion of the monetary stock of gold causes a trade cycle. For the reasoning that a change in the stock of money itself causes a trade cycle regardless of a change in the general level of prices see Mises (1912), Hayek (1929), Hayek (1931), and other works in the Austrian trade cycle tradition.

5 An interesting question is whether the occurrence of the trade cycle of the Austrian type depends on the bank reserve ratio. Let us assume that a shock boosts the monetary stock of gold. Then a part of the «surplus» gold is deposited with banks. If the banks keep only fractional reserves then the new gold deposits allow banks to expand their credit, pushing the interest rate below its equilibrium level, which drives the price level upward, and causes misallocations of investment, lengthening the production (increasing its roundaboutness), and creating an artificial boom. This is less certain in a case of one hundred percent reserve banking. In such a case it is possible that the "surplus» gold is spent in proportion to the existing money streams, not changing relative prices. However, this cannot be taken for granted, because the shock changes the relative distribution of wealth in society, see Mises (1912). Moreover, it seems highly probable that at least some of the newly mined gold would enter the credit market, thus lowering the interest rate. The corresponding trade cycle might be at least milder in this case than in the case of fractional reserve banking. However, this question requires more research before a final conclusion is reached. I am thankful to Prof. Huerta de Soto for this point (Huerta de Soto, 2006). 
Scottish type may undermine the stability of the gold standard; second, we will show that a return to the gold standard may be difficult, and even impossible without collective action of many countries of great economic power.

\section{Mature Free Banking System}

White and Selgin have shown in their influential works (White, 1984, 1999, Selgin 1985, 1988, Selgin-White, 1987, 1994, etc.) how the mature fractional reserve free banking system of the Scottish type can evolve and work-that such a banking system may have many positive virtues: it need not be fraudulent, it may be stable without bank runs and panics, banks cannot inflate at will etc.

One of the advantages of this banking system over one with one hundred percent reserves is that it economizes on gold reserves, which reasonably lowers the resource cost of money. According to White (1999, p. 46-7), the gold reserves of the Scottish banks prior to Peel's Acts were about two percent or smaller (the monetary multiplier was 50, or higher). This lowers the resource cost of money from 2.5\% GDP a year estimated by Friedman for the one hundred percent reserve banking to the negligible $0.05 \%$ estimated by White (1999) for the Scottish-type banking system.

However, this advantage is not free: it may undermine the stability of the gold standard, if spread to all gold-standard countries. It is so because it decreases the monetary stock of gold reasonably-about 50 times, according to White (1999), in comparison to the one hundred percent reserve banking. In such a case we have no guarantee that such a small monetary stock of gold is big enough to protect the gold standard countries reasonably against the 'gold' shocks. It may be such, but it is not certain at all-it is an empirical question which cannot be solved using data from the 18th or 19th century because the average reserve ratio, and the monetary stocks of gold were much higher in those days than they would be in the hypothetical worldwide free banking of the Scottish type. Selgin (1988, p. 129-133) is then misguided when he uses historical evidence from those days to 
prove the stability of the mature fractional reserve free banking system. Such evidence is irrelevant.

Of course, this conclusion does not hold true for the mature free banking system of the Scottish type only, but for all monetary systems economizing on gold reserves, e.g. for the gold exchange system (if widespread), and the like.

\section{Monetary Reconstruction}

Some Austrian economists, e.g. Rothbard (1983), or Hülsmann (1998), proposed plans to reestablish the gold standard and free banking. Their proposals did not require any political coordination between countries. Hülsmann (1998), in his proposal for liberal monetary reform, even says that such a reform plan must be feasible in a single country-he can clearly see that collective action of many economically powerful nations is in the near future improbable, and could lead to many unwelcome compromises.

The authors of these proposals usually suppose without questioning that the gold standard would be as stable nowadays as it was in the 19th century and earlier. However, our hypothesis predicts that if only a single country returns to the gold standard, it might suffer from serious price instability and recurring trade cycles, since its monetary stock of gold would be most probably tiny in comparison with the world 'gold' shocks. It holds true for small countries; if any great country could have a monetary stock of gold big enough to protect the country reasonably from shocks is an empirical question.

Moreover, in a world where gold countries without central banks coexisted with countries with fiat money issued by central banks, the 'gold' shocks could be even more severe than in a purely commodity standard world. This is because the demand for the non-monetary stock of gold would rise whenever people in the fiat-money countries expected political instability, or a rise in domestic inflation etc., because they use gold as a hedge. The supply of gold would rise whenever central banks or other state or international agencies sold a part of their gold holdings, 
or increased the limits on their gold leases. Another possible source of instability could be the market for gold derivatives. ${ }^{6}$ Other shocks could be caused by attempts of other countries to reestablish the gold standard, or to leave it, as was experienced in the 19th century. Even the large monetary stocks of gold of those days were not big enough to isolate gold countries reasonably from price level volatility caused by this factor.

We can present here only very rough calculations to grasp the empirical importance of this thesis since all estimates depend critically on market prices that are (nowadays) extremely volatile. Moreover, these prices would be altered significantly by any reform of the monetary system - at least by a reform done in an economically strong country. We have to explore two questions: first, how much price level instability a country going to the gold standard would suffer if its monetary stock of gold was too small to stabilize its price level? Secondly, could the monetary stock of gold of a single country be big enough to stabilize its price level reasonably?

We can obtain the answer to the first question very simply by calculating the rate of inflation of a hypothetical currency based on gold in the limit case when the monetary stock of gold is nil. We use data on gold prices over the period of the last four decades, see Figure 4. If the price of gold in USD is $p$, and the US price level is $P$, then $p / P$ is the price of gold in terms of goods, and $P / p$ is the price of goods in terms of gold, i.e. the price level based on gold, see Figure 5. For the inflation of this 'gold price level' see Figure 6.

The 'gold inflation' has a very low mean value-almost zero in the whole sample starting early 1971 and ending early 2006, and about $3.4 \%$ in the subsample starting in 1982 (we have used an arithmetic average of monthly calculated p.a. inflation rates) but it is highly volatile ranging from less than $-20 \%$ to more than $30 \%$ even in the more stable period since 1982. Its standard deviation is $22.3 \%$ in the whole sample, or $12.7 \%$ in the later

6 The impact of the derivatives market on the spot price of gold is very complex, and depends critically on the behavior of the official holders of gold (central banks, state and international agencies etc.). For an analysis see Neuberger (2001). 
FIGURE 4

NOMINAL AND REAL PRICE OF GOLD (USD/TR.OZ)

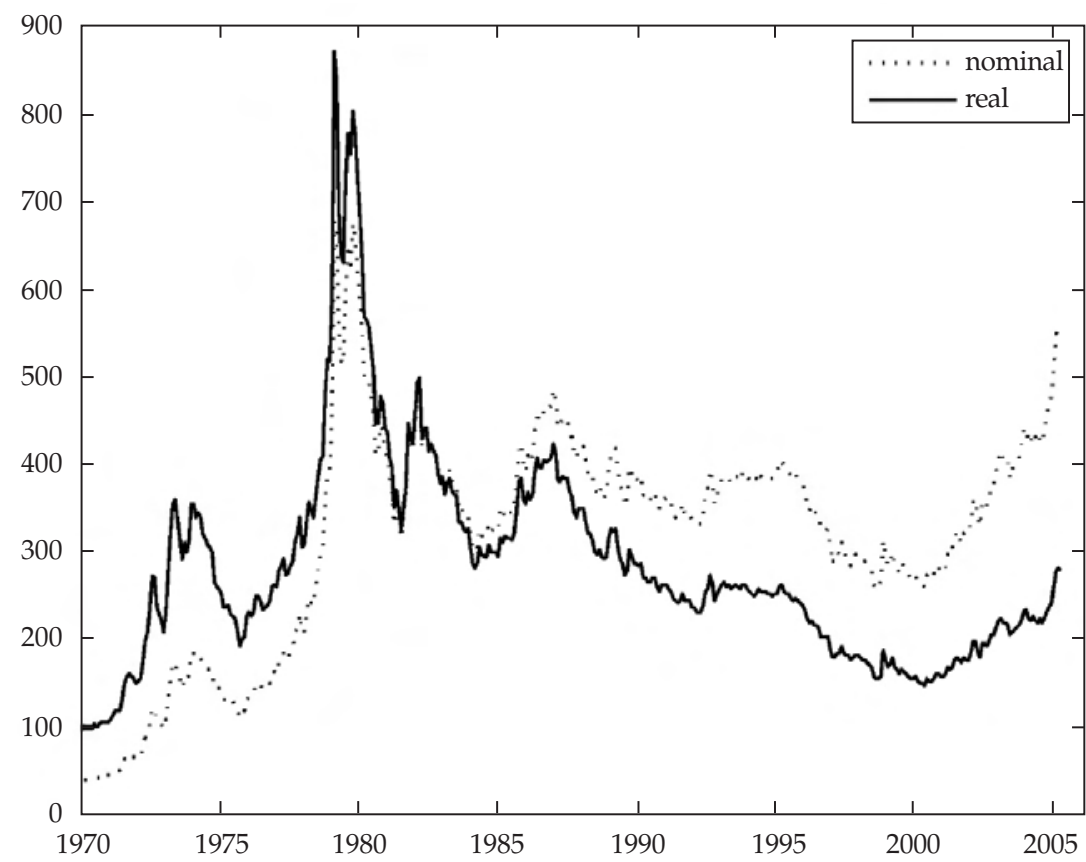

Nominal and real prices of gold in USD per tr. oz. Real values are deflated with the US CPI index. Source: The USD price of gold: World Gold Council (www.gold.org); the US CPI index: BLS.

subsample. These outcomes are clearly much worse than the performance of a general central bank in the last decades. This means that if the monetary stock of gold was too small to stabilize the gold price level significantly, the outcomes of a gold standard reconstruction would be disastrous.

Let us proceed to the second question: how probable is it that a single country can have a monetary stock of gold of such an extent to stabilize its price level reasonably? The easiest way to estimate the answer is to calculate the probable size of the monetary stock of gold of a country and compare it to the expected size of 'gold' shocks. We make four estimates: one set for a small country, and the second for a large country. For each country we calculate one 
FIGURE 5

GOLD PRICE LEVEL (CALLIBRATED TO 100 AT THE MIDDLE)

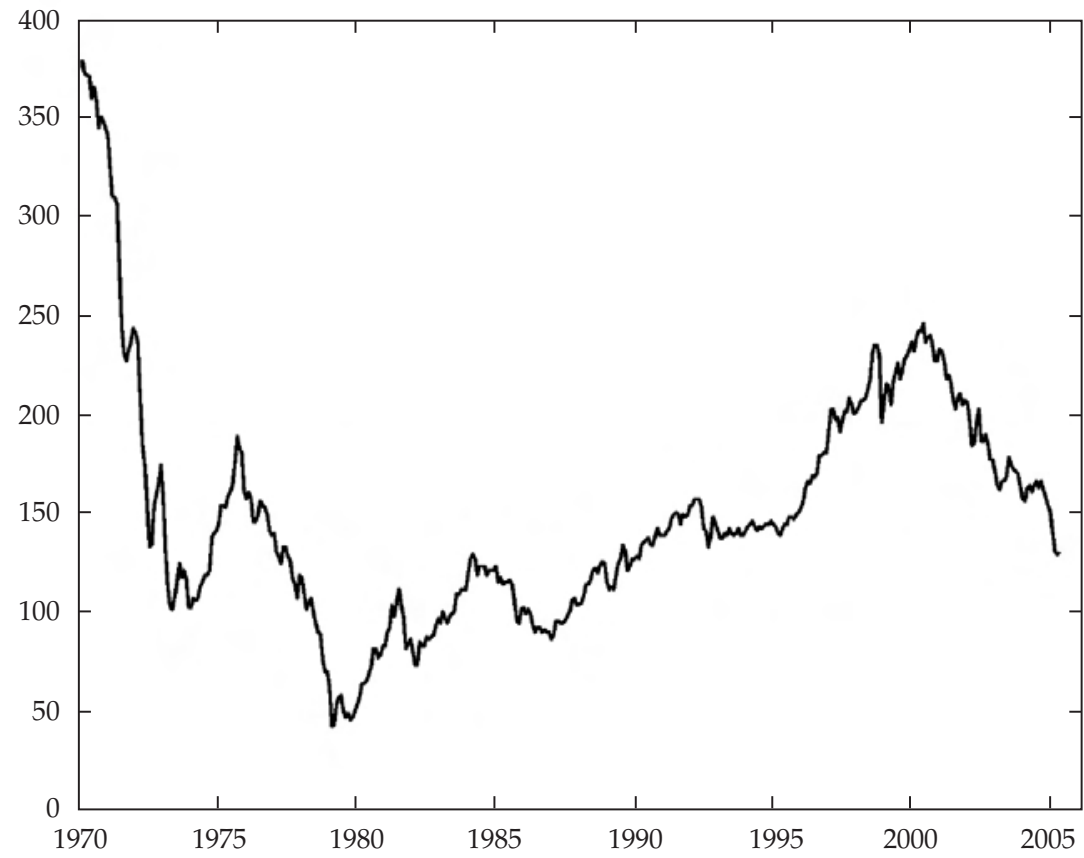

The price level of a hypothetical 'gold' currency. It is one over the price of gold in real USD calibrated for convenience to be 100 in the middle of the sample (calculated from the same data as in Figure 4).

estimate for a one hundred percent reserve banking assuming that the quantity of monetary gold is equal to the present stock of $\mathrm{M}^{7}$, and the other for a mature free banking system of the Scottish type assuming that the quantity of the monetary gold is $2 \%$ of the present stock of M2. We use data from December $2005 .{ }^{8}$

7 Such a calculation is most probably overestimated-the public is likely to hold more M1-type money when it is paid the net interest on it than when it has to pay a net warehouse fee.

8 Long run averages may be better for this purpose. However, we prefer the simpler way because the estimates are very rough, and thus a use of a more sophisticated technique would yield no real gain. 


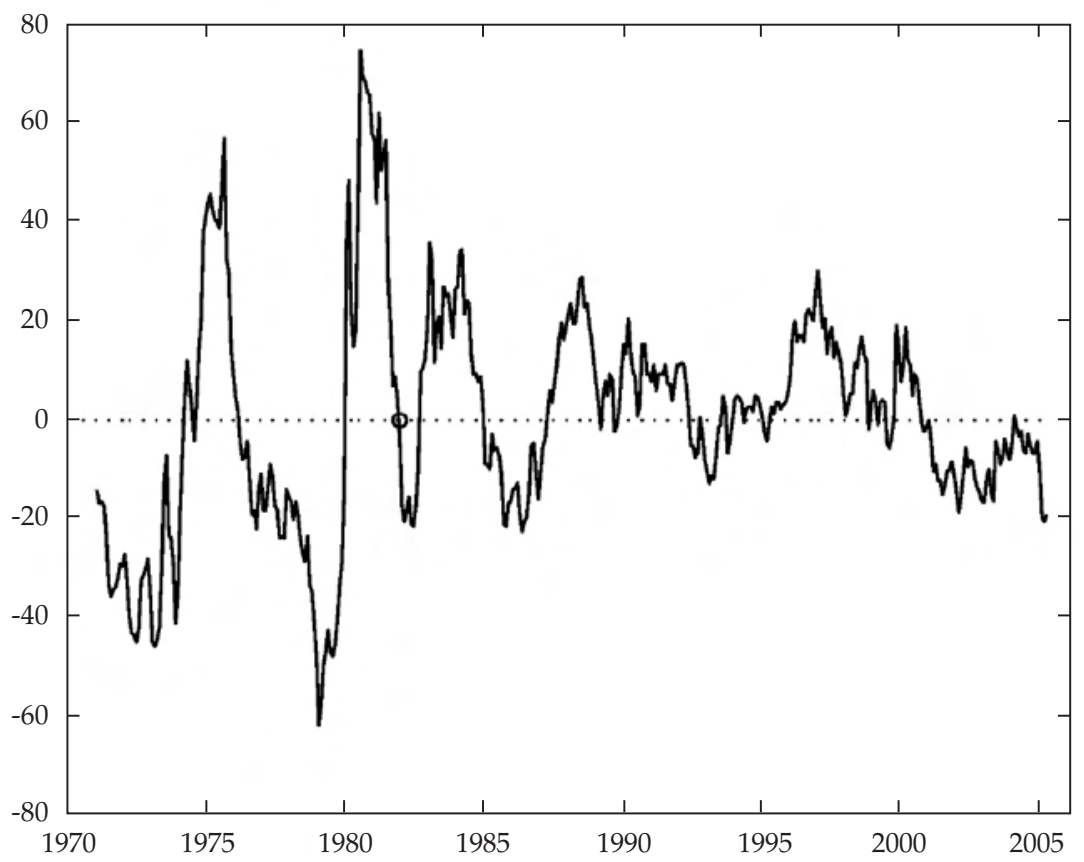

The rate of inflation of a hypothetical 'gold' currency (calculated from the same data as in Figure 4). The circle denotes the beginning of the more stable subsample.

Let us take the Czech Republic as an example of a small country, and the United States as an example of a large one. In December 2005, the Czech Republic money stock was 1,087 billion Czech crowns (M1), or 1,992 billion (M2). This was roughly 44 , or 81 billion USD respectively (the exchange rate was 24.588 Czech crowns for 1 USD). Given the market price of gold (510.0972 USD per troy ounce), the monetary stock of gold would be 2,697 tons in the case of the one hundred percent reserve banking, and 99 tons in the case of free banking of the Scottish type. The same calculation for the United States gives a monetary stock of gold of 85,187 tons for one hundred 
percent reserve banking, or 8,188 tons for the fractional reserve one. ${ }^{9}$

These estimates are not very robust. The market price of gold was sometimes much higher, sometimes much lower, see Figure 4 . This can change the estimates from about two thirds of the presented numbers to their doubles. The exchange rate of the Czech crown changed during this time too, although it was far less volatile than the price of gold.

More importantly, if a country was likely to go to the gold standard, the demand for gold would rise-both within the country (for monetary purposes), and outside of it (for speculative purposes). This would drive the purchasing power of gold up-the necessary equilibrium monetary stock of gold would thus be much lower than the estimates presented above. This effect need not be very important in the case of the Czech Republic, or the United States with the Scottish-type free banking but it would be extremely significant if the United States tried to reestablish the one hundred percent reserve gold standard because the quantity of gold necessary at the present price to reestablish it constitutes more than one half of the above-ground gold stock (about 85,187 tons out of 155,500 tons, see below). Thus such an attempt would cause great gold deflation. It is impossible to guess what the equilibrium size of the monetary stock of gold would be in such a case, but it would obviously be much lower than those 85,187 tons estimated above.

The estimated size of the monetary stock of gold should be compared to the average extent of the 'gold' shocks. Alas, it is not possible because the necessary data is not available-the gold market is an OTC market, and its liquidity and volatility are not publicly known. The only available data are the estimates of the World Gold Council. It estimates the world total aboveground stock of gold as about 155,500 tons in 2005. The quantity of newly mined gold increased from 2,469 tons in 2004 to 2,520

9 Source: The Czech Republic money stock and the Czech crown-US dollar exchange rate: The Czech National Bank (www.cnb.cz); the US money stock: Fred, the Federal Reserve System at St. Louis; the US price of gold: World Gold Council (www.gold.org). 
tons in 2005 (i.e. by $51 \mathrm{t}$ ), the total mine supply (due to hedging) from 2,042 to 2,407 tons (i.e. by 365 t). The total year «end-user consumption» 10 increased from 3,190 tons in 2003 to 3,496 tons in 2004, and to 3,727 tons of gold in 2005 (i.e. by 306 ton, or 231 tons per year respectively). From the statements and charts of WGC it can be learned that these quantities have been quite volatile in the past, and the quantity of above-ground gold has increased reasonably in the last decades (about $64 \%$ of it has been mined since 1950). ${ }^{11}$

Even though our data is not conclusive, rough proportions are clear. The monetary stock of gold estimated for the Czech republic $(2,697$ tons, or 99 tons respectively) is of the same order as the year production, or the "end-user consumption», or is lower. The same holds for the monetary stock estimated for the United States on the fractional reserve banking system ( 8,188 tons). Therefore, it seems reasonable to believe that usual shocks stemming from the gold market could destabilize the price level of such a country to a great extent. On the other hand, it seems possible that a sole country of the economic strength of the United States could perhaps stabilize the 'gold' price level if it had installed one hundred reserve free banking but even in such a case it cannot be taken for granted since the size of the corresponding monetary stock of gold cannot be guessed.

\section{$\mathrm{V}$ \\ CONCLUSION}

In this paper we have hypothesized that the price level stability of the gold standard to 'gold' shocks depends critically on the size of the monetary stock of gold relative to the extent of these shocks. Every change decreasing its relative size lowers its price level stability. Since the price level instability is usually associated

10 The «end-user consumption» defined by the World Gold Council includes production of new jewelry, industrial and dental use, and investment. This is not identical to the theoretic concept of consumptive use mentioned above.

11 See the web site of the World Gold Council, www.gold.org 
with trade cycles, we have to assume that every such change decreases also the overall macroeconomic stability in a broad sense.

If our hypothesis is correct, it has some consequences that Austrian economists may not like: first, the mature fractional reserve free banking of the Scottish type may undermine the stability of the gold standard. Historical records of its stability in the 18th and 19th century are irrelevant since they are built upon a system with a much higher monetary stock of gold than that which would be associated with a hypothetical worldwide free banking of this type.

Secondly, an attempt to reestablish the gold standard would probably have to involve the collective action of many countries of a great economic power. If a single small country tried to resume gold, its monetary stock of gold would be small relative to the world gold market shocks, and the economy could be destabilized by 'gold' shocks. This means that a return to gold may nowadays be a very difficult task even if we neglect all problems associated with the initial transition of the price level to its new long run after-the-resumption equilibrium (i.e. initial deflation), which could be a serious problem indeed. This all makes the return to the gold standard rather improbable in the near future. Obviously, it is much easier to spoil something good which evolved over centuries in the twinkling of an eye than to create it again.

Advocates of the free banking system should then perhaps abandon attempts to reestablish the gold or other single commodity standard, and explore other possibilities such as a symmetallic standard, a commodity reserve currency, or the system proposed by Selgin (1994): a Scottish-type free banking based on a fiat monetary base of a forever-frozen quantity. There may be other systems of government-free money that could work well too-better than both the present system, and the dangerous transition to gold. 


\section{VI \\ APPENDIX}

Let us sketch how the major thesis of this paper may be derived in a more formal way. We cannot solve it here completely since it would require many special assumptions to allow us to solve the differential equation (7). However, even its informal treatment may yield some insight.

The quantity of money $M(t)$ at time $t$ is equal to the size of the monetary stock of gold $G_{m}(t)$ times the monetary multiplier $\mu$.

$$
M(t)=\mu \cdot G_{m}(t)
$$

The quantity of money $M^{d}(t)$ demanded at time $t$ depends on the current price level $P(t)$ and on the real money balances demanded $\Phi(\bullet)$

$$
M^{d}(t)=P(t) \cdot \Phi\left(\pi^{e}(t)\right)
$$

where the demanded real money balances $\Phi(\bullet)$ decrease with the rise of the expected rate of inflation $\pi^{e}(t)$.

The actual rate of inflation $\pi(t)$ at time $t$ is the rate of change of the price level

$$
\pi(t)=\dot{P}(t) / P(t)
$$

where the dot over $P$ denotes the time derivative. (The same convention is used below too.)

The equilibrium price level is at each time determined by the demand for money (2) and the money supply (1)

$$
P(t)=\frac{\mu \cdot G_{m}(t)}{\Phi(\pi(t), Y)}
$$

The total stock of gold in the economy $G(t)$ consists of the monetary stock of gold $G_{m}(t)$, and the non-monetary stock of gold $G_{n}(t)$ where $G_{n}(t)$ is an increasing function of $P(t)$. The 
non-monetary stock of gold is at any point in time equal to its demanded quantity, i.e.

$$
G_{m}(t)=G(t)-G_{n}(t)
$$

The size of the total stock of gold $G(t)$ is not constant over time. It is increased by a quantity of newly mined gold $g^{s}(t)$, and decreased by the consumptive use of gold $g^{d}(t)$ at any moment. The rate of change of the total quantity of gold $\dot{G}(t)$ in time $t$ is

$$
\dot{G}(t)=g^{s}(t)-g^{d}(t)
$$

where $g^{s}(t)$ is a decreasing function of $P(t)$, and $g^{d}(t)$ in an increasing function of $P(t)$.

The rate of inflation at time $t$ is then

$$
\pi(t)=\frac{\dot{P}(t)}{P(t)}=\frac{\dot{G}_{m}(t)}{G_{m}(t)}-\frac{\dot{\Phi}(\bullet)}{\Phi(\bullet)}=\underbrace{\frac{g^{s}(t)-g^{d}(t)-\dot{G}_{n}(t)}{G_{m}(t)}}_{A}-\underbrace{\frac{\dot{\Phi}(\bullet)}{\Phi(\bullet)}}_{B}
$$

The term $A$ in the equation (7) is the basic cause of inflation. Its numerator is the size of the 'gold' shock-the quantity of gold that is to be added to or subtracted from the monetary stock of gold $G_{m}(t)$. It consists of the net inflow of gold into the economy $g^{s}(t)-g^{d}(t)$, and of the net quantity of gold transferred to the nonmonetary stock of gold, $\dot{G}_{n}(t)$. Each of these terms may cause the original imbalance, while the other one dampens it in such a case. The size of the 'gold' shock (the numerator) is independent of the size of the monetary stock of gold $G_{m}(t)$, which is the denominator of the fraction. It means that other things being equal, given the shock, the rate of inflation or deflation is higher, the lower the monetary stock of gold $G_{m}(t)$ is.

The term $B$ in the equation (7) is the rate of change of the real money balances held by the public. We know empirically that a modest rate of inflation does not change the real money balances, so usually we may neglect this term altogether; and even in the case of hyperinflation, it is of a secondary importance. Moreover, 
it does not change the result: if the rate of inflation rises in the time, it enhances the rise, since the public tries to lower its demand for the real money balances $(\dot{\Phi}(\bullet)<0)$. If inflation slows down, it slows it down further, since in such a case the public increases its real money balances $(\dot{\Phi}(\bullet)>0)$.

\section{BIBLIOGRAPHICAL REFERENCES}

Barro, Robert J. (1979), «Money and the Price Level under the Gold Standard», The Economic Journal, (89)353: 13-33.

Chappell, David and Kevin Dowd (1997), "A Simple model of the Gold Standard», Journal of Money, Credit, and Banking, (29)1: 94-105.

Dowd, Kevin And Anthony A. Sampson (1993), «A New Model of the Gold Standard», Canadian Journal of Economics, (26)2: 380-391.

HAYEK, FRIEDRICH, A. (1966 [1929]), Monetary Theory and the Trade Cycle, Augustus M. Kelley Publishers.

- $\quad$ (1935 [1931]), Prices and Production, Routledge.

Huerta de Soto, Jesús (2006), Money, Bank Credit and Economic Cycles, Mises Institute.

HÜLSMANN, JÖRG G. (1998), «Liberale Währungsreform - ein Entwurf», Eigentümlich Frei, 4.

LAWRENCE, COLIN (2003), Why is gold different from other assets? An empirical investigation, World Gold Council, available at www.gold.org.

Mises, Ludwig (1980 [1912, 1952]), The Theory of Money and Credit, Liberty Fund.

Neuberger, Anhony (2001), Gold Derivatives: The Market Impact, World Gold Council, available at www.gold.org.

RADFORD, R.A. (1945), «The Economic Organization of a P.O.W. Camp», Economica, (12)48: 189-201.

Robertson, Dennis H. (2000 [1922]): Money, Routledge, the 4th edition.

Rolnick, Arthur J. And Warren E. Weber (1997), «Money, Inflation, and Output under Fiat and Commodity Standards», The Journal of Political Economy, (105)6: 1308-1321. 
Rothbard, Murray N. (2004 [1962]), Man, Economy, and State, the 2th edition, Mises Institute.

Rothbard, Murray N. (2000 [1963]), America's Great Depression, the 5 th edition, Mises Institute.

- (1983), The Mystery of Banking, Richardson \& Snyder.

Selgin, George A. (1985), «The Case for Free Banking: Then and Now», Policy Analysis, 60, Cato Institute.

- (1988), The Theory of Free Banking: Money Supply under Competitive Note Issue, Cato Institute.

- (1994), «Free Banking and Monetary Control», The Economic Journal, (104)427: 1449-1459.

Selgin, George A. and Lawrence H. White (1987), «The Evolution of a Free Banking System», Economic Inquiry, (3)25: 439-57.

- (1994), «How Would Invisible Hand Handle Money», Journal of Economic Literature, (32)4: 1718-1749.

White, LAWRENCE H. (1984), Free Banking in Britain: Theory, Experience, and Debate, 1800-1845, Cambridge University Press.

- (1999), The Theory of Monetary Institutiones, Blackwell Publishers. 